\title{
Internet of Toys across Home and Early Childhood Education: Understanding the Ecology of the Child's Social World.
}

Arnott, L, Palaiologou, I. \& Gray, C.

\begin{abstract}
This article presents findings from an on-going international study of children's use of internet-connected toys (IoToys) across Scotland, England, N.Ireland and Greece. We sought to investigate practices with IoToys across homes and early childhood settings. Data from 12 Case Study families and approximately 200 children who interacted with Case Study children in early childhood settings were collected alongside interviews with parents and Educators. Findings indicate that a digital disconnect is recurring due to infrastructure and budgetary issues in early childhood settings, resulting in organic play-based IoToy use at home versus structured adult directed teaching of IoToys in early childhood practice. Working from a social-ecological theoretical frame demonstrated that children fluidly transitioned between digital and non-digital play and across diverse socio-ecological contexts of home and early childhood settings.
\end{abstract}

Keywords: Digital Childhood; Internet of Toys; Ecologies; Home/Education Divide; Play; Early Childhood Education

\section{Introduction}

The use of internet-connected toys (IoToys) in households in developed countries is increasing but Early Childhood Education (ECE) still resists their inclusion (Gray et al. 2017). Mascheroni and Holloway (2017) examining the reasons for this divide between home and ECE argue that discourses around children, media and technology are dominated by cultural pessimism, media euphoria and a critical-optimistic approach, which tend to be polemic towards the potentialities of IoToys in ECE. The dominant ideology in ECE, framed around traditional experiential, sensory and physical play, fuels this anxiety because technologies - still imagined around screen-based media - 
are not currently viewed as an appropriate platform for providing traditional play experiences (Palaiologou, 2016a). The result is continued discussion of digital disconnect or difference in children's digital experiences, between home which is fluid, exploratory and naturalistic and ECE which is structured, timetabled, or indeed, non-existent (Edwards et al, 2017).

As part of a qualitative study, we present Case Study evidence of children's lived experiences with IoToys across home and ECE to examine the practices employed. It is proposed that the tangible nature of IoToys, coupled with children's empowered use of technologies (Craft, 2012) provide a platform to entangle formal and informal learning experiences of children. IoToys allow for an alternative theoretical conceptualization of children's engagement with digital devices as social, collective, contextual and interlinked within a digitalized social world. In doing so, IoToys offer opportunities for varied play that fits, rather than competes, with traditional ideas of play in ECE.

\section{The Home/Education False Dichotomy}

From birth, many children in developed economies enjoy an increasingly sophisticated range of IoToys connected to online platforms (Mascheroni \& Holloway, 2017). According to Holloway and Green (2016), unlike conventional resources, technology respond to and interact with children. Consequently, the nature of play is changing, becoming ever more complex as children move between online and offline spaces (Marsh et al. 2015).

The popularity of digital technology lies in its malleability, portability and in the instant feedback it offers a child (Arnott, 2017; Gray et al., 2017). Yet, opponents argue that digital technology pollutes childhood rendering it 'toxic' (Palmer, 2015), threatening 
children's imaginative play (Levin \& Rosenquest, 2001) and impacting negatively on the developing brain (Kardaras, 2016). The evidence base for these claims is thin and ambiguous. Nevertheless, the negative publicity associated with young children's engagement with digital technology, may explain why it is used under strict adult supervision (Gray et al., 2017), with activities limited and time on task micro-managed in ECE.

Children's home and ECE experiences are thought to operate in mutually exclusive worlds with children adjusting their notions of play and learning accordingly (Arafeh \& Levin, 2003). The home/ECE discourse - as spaces which are disconnected and disjointed - has been used to critique the lack of technology in ECE. Edwards et al., (2017) critique the discourse because it implies that ECE settings should emulate the child's home life. This assumes that all ECE providers have the same access to training and ongoing technological CPD, whilst ignoring individual teachers' beliefs about the role of technology in ECE (Edwards et al., 2017). The impact of diminishing ECE budgets have on access to materials is also disregarded. Thus, Gray et al. (2018) argue against this simplistic notion of disconnect across contexts, on the grounds that it is based on a range of generalisations.

Scott and Marsh (2018) argue that practices within and between contexts have a strong influence on the digital experience. Yet childhood is continuously changing, "not just technologically, but also socially and culturally ....contemporary childhoods are shaped by and, in turn, shape the changing communicative practices of the twenty-first century" (Marsh, 2005, p. 1). Given the unprecedented impact IoToys have had on children's lives in the developed countries, it is advisable to avoid artificially constructed binaries 
of "traditional and new," (Merchant, 2007, p. 241) or good versus bad practice. Instead as Craft (2012) proposes, we should view children as agentic and attempt to interpret their experiences from a compelling nexus of diverse materials and social interactions. Thus, we have argued that children's play in the digital world should be viewed through a social ecology lens in an effort to understand the "wholeness" of children's play and learning at home and ECE.

\section{Theoretical approach}

The theoretical approach to this research is derived from a synergy between developmental psychology and social ecology theory. Developmental psychology examines play as a mental behaviour whilst social ecology conceptualises human behaviour as a function of ongoing interactions among multi-contexts within which children live and learn. The combined positioning of both offered us the "wholeness" of examining children's play. We argued that children's technological experiences are oriented in different "moulded" landscapes: mentally, physically, socially and culturally. Building on theoretical unpinning around contextualism (Tudge, 2008), EcoCulturalism (Weisner, 2002), Ecological Systems Theory (Bronfenbrenner, 2009) and Pedagogic Cultures (Arnott, 2018) with consider this project from a social ecology perspetive. In doing so we seek to understand the wholeness of the child's play situations with IoToys across digital and non-digital social landscapes.

Our previous analysis led us to conclude that in relation to IoToys, children's socialecological worlds encompass an:

1. Ecology of self (self as a psychological construct encompassing experiences or acts on the IoToys). 
2. Ecology of Exosphere (the child in relation to other social beings)

3. Ecology of the Social World (the cultural experiences in context i.e. across home or early childhood context).

Across these ecological realms, the child fluidly entangles digital and non-digital play. The digital is engrained in their lives and children do not make the distinction between digital and non-digital, as adults do. The tactile/tangible nature of IoToys, solidifies this fluid transition between digital and non-digital.

In this paper, we analyse the continuity of the entangled play that IoToy offered and we discuss its integration across home and ECE. Although we present evidence here which is pertinent to each of these ecological contexts, the central tenant of this paper is the fluidity with which children transition across social worlds of home and ECE. Thus, this paper pertains primarily to the Ecology of the Social World. Within this frame, we see children expertly manoeuvring on- and off- line spaces as they embrace the entanglement of digital and non-digital realms in their play. Similarly, they expertly manoeuvre ECE and home play spaces with technologies. The child is the expert in their own digital play across both contexts as they interpret perceived differences in play influenced by the Social World they inhabit. It is here that we see the potential for a social-ecological lens to provide complementarity for digital spaces to act in a supportive role to perpetuate the integrity of a play-based practice, reducing the focus on segregated practices between home and ECE.

\section{Aims of this Paper}

This paper focuses on the social and cultural world of entangled digital/non-digital play across home and ECE, addressing the following research questions: 
1. In what ways are IoToys integrated into home and ECE across Scotland, England, Northern Ireland and Greece?

2. What are practitioners, parents and children's perceptions of IoToys for play at home and in ECE?

3. To what extent can IoToys shift perceptions of the role of technologies in ECE?

\section{Methods}

This paper presents a snapshot of one finding strand - the social and cultural world of entangled digital/non-digital play across home and ECE - from the first year of an active study. Data were primarily collected using a Case Study approach (Yin, 2013) of three families, their children and Educators ${ }^{1}$ in early childhood settings ${ }^{2}$ in each of our four cohorts: England, Scotland, Greece and Northern Ireland. The amalgamated data set for the whole project consists of 12 Case Study families. Across the contexts, the sample represents a relatively affluent group, with high achieving early childhood settings which were not in areas of real disadvantage and what could be typically described as 'middle class'.

As siblings were included in family Case Study data, we collected observational data from 25 children aged from $2-6.5$ years at home and in their settings. In addition, up to 200 additional children were potentially included in the project if they interacted with

\footnotetext{
${ }^{1}$ To unify the varied terminology and qualifications of staff across the data cohorts, we use the encompassing term of "educator" to describe the staff.

${ }^{2}$ As the names applied to ECE vary across the project when we refer to ECE we will use the term "settings".
} 
the Case Study children in settings as part of the play. We also collected data from parents and Educators through interviews and multimedia messaging. Further data were collected from children directly through play-based conversations with them relating to the multimedia data from parents and photos from the observations we had undertaken. The children's data was initially planned around the PhotoVoice approach (Moxley, Bishop, \& Miller-Cribbs, 2018), however in order to mirror play-based practice and develop age- and pedagogically- appropriate methods for the children, some conversations evolved into arts-based research approaches, storyboarding or storytelling (similar to Blaisdell et al., 2018). Across this project, EECERA (2015) Ethical Code of Practice was adhered to and approval was sought from appropriate university committees. Children's rights was paramount and good ethical practices ensured their rights were always respected.

\section{IoToys}

Across the cohorts there were varying degrees of familiarity with IoToys in the home, while no settings owned IoToys prior to the study. A combination of observing children's established interactions with their owned IoToys and purchasing IoToys to loan to families and settings, was employed. We avoided all IoToys which had previously been criticised for security breaches (e.g. Gibbs, 2015) and the chosen resources were loaned to each setting and home, where required. Where IoToys were loaned to families and settings, we requested that children used the toys in a manner that reflected their typical technology integration and therefore there was no specific requirement to push for IoToy use at regular intervals or specific times. In some cohorts, while IoToys were welcomed in families, they were not integrated into settings, even when offered on loan. These settings remained in the project to maintain balance 
in the data set.

\section{Analytical Frame}

The social-ecological theoretical frame that informed this study was broad and holistic. As such, one singular analytical model/tool was not adequate to interpret the data across the multiple ecological realms. A more pragmatic, entangled and emergent approach was adopted, which drew on key interdisciplinary frameworks within each ecological realm. In essence, the data were thematically analysed in relation to ecological realm, Given the diverse locations of the data collection, each cohort's data (Scotland, England, N.Ireland and Greece) was analysed separately by each local research team. To ensure consistency across the teams, 'a priori' coding structures were used (see Appendix 1). We then conducted a comparative analysis from the analysed findings to draw relevant conclusions.

\section{Results and Discussion}

Analysis of the Ecology of Social World demonstrated three key findings:

1. There continues to be a digital disconnect between home and ECE; one that will never erode while technological developments - such as the emergence of IoToys advance at a greater pace than the preschool infrastructure (in terms of hardware and connectivity).

2. Home and ECE practices offer divergent experiences with IoToys, driven by differing ecological learning structures and technologies practices in both contexts.

3. The child is positioned as expert and knowledgeable in their Ecological Social World involving IoToys, creating a potential platform for synergy of play practices across social world. 
Finding 1: Digital Disconnect Fuelled by Infrastructure

Our research reiterates the position of previous work that children's technological experiences at home are generally fluid and integrated into everyday lives, as part of everyday experiences (Plowman \& McPake, 2013). Videos submitted by parents showed children tinkering with IoToys, pressing buttons to evoke a response and learning how to operate the device during unstructured interactions. Children and siblings were generally free to interact with the resource around clubs or extracurricular activities; some parents in their dialogue talked about the lack of use of the IoToys at certain points in the study due to it being a busy period for children's clubs or family events. Parents, although not directing the play were close by to offer support and advice at children's request.

In most cases, children's access to IoToys appeared organic and at the child's request, or indeed the resources were freely available to use at a time convenient to children and/or parents. Families seemed to have appropriate infrastructure to support easy setup of the resources and appeared comfortable with children using technologies. Only 1 Case Study family indicated a lack of infrastructure to support children's free access to the IoToys as they only had one iPad to connect to the resources and often their father took the iPad with him for long periods while he worked off shore; this family described themselves as a technology free household.

From the remaining families, the free-flow access was so great that in some cases it resulted in the parents voicing concerns about children's perpetual interest in digital devices, drawing on terminology that resonates with moral panics (Palmer, 2015): 
"I would say in the last month both my 3 yro and 5yro have developed a voracious appetite for games in phones and ipads. They are now asking for them all the time, like they're addicted!".

In early childhood settings, in some data cohorts [Greece and one setting in England] lingering perceptions of technologies as not 'real' play or resources, perpetuated a purposeful and conscious digital divide with IoToys not finding a place within the formal learning practices of the settings.

For other settings, where Educators were keen to adopt the IoToys into their practice, there appeared to be an on-going issue with physical infrastructure that hindered the integration of IoToys. Wi-Fi speed and dependability of connection caused problems for using internet-devices in general, which had a knock on effect for the IoToys use as demonstrated by Laura:

Laura indicated that one of the issues with technology is the problem with Wi-Fi and the speed of the Wi-Fi. They are now using e-Journals for their documentation processes and they said they couldn't access their e-Journals for a week because of Wi-Fi issues. (Extract from researcher field notes)

And even in cohorts where the Educators were enthusiastic about the IoToys and had successfully navigated any infrastructure issues, their budget constraints not only shaped the long-term possibilities for the integration of IoToys but also propelled the need for technological experiences to be less child-led/centred and more adult-led (Fisher, 2013). The overriding concern for practitioners was that IoToys were expensive and fragile and it became almost impossible to justify free-play with such valuable resources for fear of them being damaged. This meant that IoToys become disjointed resources which are used a planned structured moments, rather than a freely available resource which could be used in line with traditional early childhood 
philosophy of child-led discovery. The following extract, demonstrates how teachers came to the conclusion that IoToys were more suited to structured adult-led play:

Diane: We kind of move around areas every week, so I kind of to try and incorporate it into kinda what I'm doing each week in that area and they [children] seem to really love it.

Researcher: So do you think there's longevity in it then? Because one of the question we were asked was 'do you think children's just like it because they're novel?'. Can you see it being integrated long term?

Diane: I think it could. I was speaking to Laura [practitioner] and she was saying actually you know it would be really great if we could just buy some of these ourselves and have them. But, I think although we want the kids to do it on their own and be very independent, I think they still have to be very monitored with them, in terms of, they can be quite heavy handed, you know. But going forwards $100 \%$ want to definitely buy some if we can get the funds to do so, em, but I think it will be one of those things that we maybe bring out when a staff member is in the vicinity. (Practitioner Interview Transcript Extract)

No matter how much work is undertaken to evaluate the digital disconnect between home and education or indeed reframe discussion (e.g. Edwards et al., 2017), the fastpaced evolution of digital toys and associated connectivity requirements, mean that publically funded education cannot stay abreast of the advances in the same way that families can at home ${ }^{3}$. As such, we will continue to see an ongoing ebb and flow of the digital disconnect between home and settings with each new iteration of technological toy emerging because public funding will continue to lag behind the development of resources. Here we see a role for national education policy and local authorities in evaluating the support systems in place for technology use in ECE. To meet

\footnotetext{
${ }^{3}$ The families for this study represent a relatively affluent demographic.
} 
Government targets around technological integration, these infrastructure requirements need to be addressed more readily.

For children, however, this disconnect was not problematic as they fluidly transitioned both across the entanglement of digital and non-digital play and across diverse socioecological contexts of home and settings.

Finding 2: Divergent Experiences: Ecological learning structures and technological practices across home and ECE.

Children's experiences with IoToys mostly differed across home and early childhood settings: play and interaction with the IoToys in the home was reminiscent of older studies of technologies where children just 'pick it up' (Plowman, McPake, \& Stephen, 2008); while settings offered a more structured, almost didactic teaching experience around IoToys.

While much research has emerged which has propelled the focus on digital play and the possibilities for understanding a more play-based integrated agenda for technologies in settings (Edwards, 2013), findings from this study suggest that in practice with the integration of novel technologies - such as IoToys - the experience reverts back to a structured, adult-led, curriculum driven agenda. For the most part, Educators considered the properties of each resource and aligned each resource to specific curriculum areas or topic. Practitioners planned activities based on their timetabled curriculum and then selected those resources which suited their planning. The extract below shows Diane recalling how they planned their pedagogy before justifying which technologies were chosen to suit the planned activity: 
After that, I think we were [due to study] maths so we had [chosen] Osmo [a hybrid toy that offered numeracy based activities]. And then we moved on to outdoors [in our timetable] and we had the wee magnifying glass [TTS DigiScope - a digital technology which was portable and appropriate to explore objects outside]. (Interview Transcript Extract).

This level of analysis continued as Educators evaluated the curriculum content which could be tapped into when using the resources, and in some cases, suggested that the resources were a way to engage children in curriculum content that they do not typically like to do. The following extract demonstrates how one of the hybrid toys offered a mechanism to engage boys with mathematical concepts; a curricular focus they don't typically enjoy:

Laura: "There's a lot of mathematical language for us. Em, loads of maths. And there's a lot going on because you've also got to watch, meanwhile putting your animal on and whatever else, you've got to watch those little numbers, I mean because they start to go back the way. It's a good opportunity for us to talk about when the numbers are going backwards, instead of because we're always talking about forwards...And when the numbers are going down, they're going that wee octopus, he's not getting any luck, so we need to feed him. So they need to watch and they need to do it quick because if not (stopped sentence). And Endangered. It talks about being endangered. So there's a lot of really good language[...]The thing I'm finding, you are engaging boys more, because it's appealing to the boys. The boys don't want to sit at a table and do maths activity with sorting activities, but they don't realise how much maths activities they're actually getting out of that [hydrid game].” (Educator interview talking about hybrid stacking game).

Thus across the country cohorts, the 'educational' IoToys - ones that were perceived to link to academic learning - were favoured by Educators in settings, 
particularly because they eased justification for their integration. The Educators saw the value of IoToys in their educational benefits, as well as for encouraging certain types of learning. The following quote demonstrates how practitioners recognised the educational content of Osmo, particularly for offering an engaging route to lure children in:

When we want to do phonics it is helpful to motivate them with Osmo [hybrid toy with a literacy option] as naturally they do not want to come and do [traditional] phonics, they prefer to run around. (Extract from Practitioner Interview).

In this sense, the practitioners framed the technology as a "carrots" to attract the children to more "educational play" for when they wanted the children to do "some work". They were using IoToys to "seduce" children to an activity like numeracy or literacy.

This academic learning was solidified by predominately structured practice, in some instances because Educators felt that children would only learning from the resources if supported by adults, due to age. The following extract demonstrates the practitioners' concerns with children's competence to engage with the resources and details why she believed that adult-led play was more suitable for the children.
So I was speaking to Laura about this [the requirement for adult led activity] the other day and I think as far as, you know Beasts of Balance, for instance, is kinds above their level in a way. She's said she's left them to try it out and it's just kinda not happening. She said, maybe they will eventually when they get used to it and things, but for now, it needs to be adult-led. (Practitioner Interview Extracts).

Even with resources that one might consider to be more tailored towards the age group and offered more child-led experiences - because of their easy interface and robust mechanisms - practitioners favoured the adult-led curriculum focus and structured 
approach. In these instances the Educators still facilitated specific 'learning' activities in an adult-let rather than play-based manner, as shown below.

Researcher: Did they use it individually, you know like they were taking the pictures, or was there any collaboration that went on around it? Diane: So there was a group of children around but they were doing it one at a time. So they would have the ipad with them and we went outside and collected things from the garden, brought them all inside, put them all out on the floor, got the microscope, then one at time they would try do, try to focus it see if there was anything they could see, if there was anything on the leaves or anything, taking the picture and then would pass it round. So that's how we worked it, so they were each getting their own wee independent shot and they could see it on the screen. They actually really liked that. (Digiscope Practitioner Interview Extract)

In homes however, parents were less concerned about the academic potential from the IoToys and rather talked about enjoyment with resources. The following parent discusses children's affection and enjoyment from using IoToys at home.

"I actually only used the beebot [bluebot] and the magnifying glass [TTS Digiscope]...both my daughters aged 2 and 4 loved them as it's a change from what they're used to playing with - we $\mathrm{r}$ [are] pretty much technology free usually" (parent dialogue).

In this case, parents did not look to IoToys for their learning potential but instead they were included into their repertoire of toys. Parents did talk about their potential but they talked about the ways it fitted in with their play and interaction, rather than academic learning, as shown in the following two extracts. 
I think Cozmo is such a brilliant toy you really need few weeks of it. Fitting it in between clubs etc. Toy [Cosmo] offers so many opportunities for children to explore and discover. (Parent dialogue).

I really think Cosmo has had a big impact. He speaks so fondly of it, as if it were human! (Parent dialogue).

In some cohorts, parents specifically avoided academic learning toys entirely:

"[my children] are at school from 7:45 until 16:00 some days, when in school all they do is educational play but when I pick them from school, I want them to play at home, so I do not want educational toys surrounding them all the time, they need a break". (parent interview)

"Enough with educational toys! [original emphasis] I want my children to play with just toys. they spent at least 8 hours in the nursery where all is about educational toys, when they come home I want them to play, so we want at home only toys that they can play" (mother of two boys ages $2 \mathrm{yrs}$ and months and 5yrs)

Here we see quite diverse learning structures and different technological practices. In Settings we see a structured adult-directed experience (Fisher, 2013) focused around academic attainment of specific curricular areas, while in home we see play-based or playful exploratory interactions with IoToys, focused around enjoyment.

It is clear from our data that parents make conscious decisions about how best to facilitate children's play with IoToys as seen, for example, from the earlier comment about wanting to promote 'non-educational' play. Furthermore, our analysis of the play experiences indicated that children are still learning with these resources, even if parents 
do not consider that to be the main use for the resource. For example, videos submitted by parents, show children developing literacy skills as they operate Cosmo, programming him to speak the names of families and friends. Similar to Levy (2009) data also demonstrated that children used the online platform to engage with digital texts.

Of particular note was how children were able to fluidly transition between the pedagogical learning experiences across their Social Worlds (home and settings). One particular Case Study child for example was able to transition, seamlessly, between individually focused interactions with IoToys in the home, to collaborative group-based social play experiences in Settings. In the home, he was intensely engaged with the functionality of the resource and even developed an attachment to the robots, interacting directly with the device. While in early childhood settings he was focused on sharing his knowledge and experience in a social context. In this sense, the robot was a useful draw to attract children to play but he was clearly more interested in the interpersonal dynamic with peers than interacting with the robot specifically; a polarised experience from the home.

\section{Finding 3: The child as expert and the parent and practitioner as novice: a platform for synergy between home and ECE.}

Despite divergence in ecological structures, particularly in relation to technological practices around IoToys, in our research across the child's social world (in home and in ECE settings) the child is competent and empowered to fluidly transition across and within the entanglement of digital and non-digital play. The newness of IoToys and adults' unfamiliarity with the resources facilitated children's empowerment. Thus, children create their unique Social World in relation to the IoToys, other agentic beings 
and the physical surroundings; one which positions the child as expert and knowledgeable. The following extract from a parent demonstrates the shift in power dynamic as the child becomes the expert or Master in the situation.

Parent Dialogue:

"I was working it [BlueBot Robot] manually and he [Child] told me we had to download an app to work it from ipad. I thought he was confused with Cosmo but He was right!

Here we see a re-evaluation of the traditional Community of Practice (Lave \& Wenger, 1991) of home and Settings where the child is typically viewed as novice. This level of engagement from children requires substantial time to tinker and discover everything that the IoToys offers; whether in independent play at homes or in a more structured experience in nursery.

It was clear that the continuity of using the same resources in both contexts, created a sense of empowerment (Craft, 2012) for children. Children in the Settings skilfully appropriated the knowledge of the resource, gained in the home environment, into the settings. Practitioners go so far as to as to suggest that children who were confident with IoToys - developed from extended use in the home - can assume the role of the adult in the Setting. For example, the interview transcript below demonstrates how a boy 'came out of his shell' after first taking home Cosmo and then assuming the adult role in nursery, facilitating the play with his peers.

\section{Practitioner Interview}

Diane: Cosmo, Larry, who's been taking it home he's been leading the, leading the whole mission. You know? All these kids come over and he's been "I'll show you how to work it" and he's showing them "and this is how you do it". So he's become the, the [inaudible] adult. He's the adult. 
Researcher: So he's the expert.

Diane: Uh huh yeah!

This recognition of the child as 'adult' or 'expert' presented a fundamental shift in the technological practices of the early childhood setting. An approach that was once driven by educator-led structured activities, evolved into a child-led and child-centred play-based pedagogical approach (Fisher, 2013). The practitioners had such confidence in the Larry's abilities with Cosmo, for example, that they entrusted him to facilitate the play within his peer group and we received videos from the nursery of Larry leading a group of children in play with Cosmo. Here we see how children are able to draw on the varied practices employed, as well as their past experience across social-ecological contexts to transform the dynamic of the situation and create a new, unique Social World. In this sense, they are creating what Bookchin described as "new potentiality for a future".

\section{Conclusions}

Digital Disconnect has been described as the qualitatively different experiences children have with technologies in their home and at school (Edwards et al., 2017, p. 1). The word disconnect implies a deficit perspective but our research suggests that this dichotomy can be to the advantage of children. Indeed, striving for synergy of playbased pedagogical practices across home and ECE may be both unrealistic and unnecessary. Rather, when recognising children's agency in a digital age (Craft, 2012), then disconnect of this nature can be seen as an opportunity to experience IoToys across the multi-layered and multi-dimensional social worlds that the children inhabit. Not only do children engage in multimodal practices with technology (Fleer, 2017; Yelland \& Gilbert, 2017) but they are in a continual state of fluctuation, manoeuvring the 
various ecologies: self, exosphere and social world, involving IoToys to entangle their play, experiences and actions in the digital era.

our critical reflection on the Ecology of the Child's Social World we see two parallels: the adultmorphic fallacy - assuming we understand the childhood digital world based on our reconstructions of childhood (in a non-digital era) and the childmorphic reality that gives recognition to the technology as natural "objects" in their lives. It can be argued that technologies are more than tools or objects because of their social and cultural capital and we are not debating this. However we suggest that instead of giving technologies unrivalled agency in our discussions, we need to give due weight to the child's agency in transitioning and manoeuvring their unique social worlds. As such, in the discussions of digitalisation, there is a need to make an isomorphic connection between children's ecologies of self, exosphere and social world. That is, instead of seeking conditions to examine technology in relation to children as external objectified mediators, we should embody technology among other things in the whole ecological system that children come to habituate. We propose that in a post digital era in developed countries that child agency is the orthodox dominant ideology and attention should be paid to the nexus of materials available to children within their social relations.

ECE needs to move beyond the passive child agenda (Craft, 2012) which raise anxieties about the role of technology in children's play (Palaiologou, 2016b), where the result is divisive discourses of digital play between home and ECE. In this paper, we argue that it is children's empowerment to be experts in their digital lives with IoToys that creates continuity across ecological contexts. As such instead of seeking continuity of technology at home and ECE, we should be concerned with the "the development of a more thoughtful, empirically grounded account of the role of media in children's 
lives" (Buckingham, 2017, p. xi). In this way, the technologies fit in with the child's Social World rather than the Social World transforming to accommodate the technology. We need to focus on "contexts so that young children can experience different modes of representations which in turn afford them the opportunity to formulate new understandings about their world" (Yelland, 2015, p. 235).

Social-ecology requires a relativist ontology where multiple realities can be envisaged in the ways children engage with digital devices to develop play opportunities. What we present here, is our interpretation of the child's relationship with IoToys in social ecological worlds. The significant advantage in this work is that it provides richness to our understanding of how children use IoToys in their play at home and ECE. As we begin to understand the multiplicity of connections across and within the child's social world, we can give weight to the overwhelmingly demanding pressures that children, practitioners and parents face, when trying to positively shape engagement with IoToys. A level of respect is required for individuals who are navigating this minefield because every play experience is unique and every learning opportunity requires different consideration.

Thinking from social-ecological lenses and an understanding of wholeness, we need to view the complexity of children's social words in terms of ecological spheres that shape and are shaped by the entanglement of play across contexts with IoToys . As such early childhood debates must move beyond divisive discourses about technologies across home and Education and instead explore the social ecology of children's play lenses to provide complementarity of spaces in a digitalised world, reducing the focus on segregated practices between home and ECE. 
Acknowledgements

The authors extend their deepest appreciation to the families, Educators and children involved in this project; not only for allowing the data to be used but also for providing the opportunity for the authors to engage in delightfully fun experiences of playing with children and technology.

Declaration of interest statement: There is no conflict of interest.

References

Allen, S., \& Whalley, M. (2010). Supporting Pedagogy and Practice in Early Years Settings. London: Sage.

Arafeh, S., \& Levin, D. (2003). The Digital Disconnect: The Widening Gap Between Internet-Savvy Students and Their Schools. Paper presented at the Society for Information Technology \& Teacher Education International Conference 2003, Albuquerque, New Mexico, USA. https://www.learntechlib.org/p/18081

Arnott, L. (2017). Framing Technological Experiences in the Early Years. In L. Arnott (Ed.), Digital Technologies and Learning in the Early Years. London: Sage.

Arnott, L. (2018). Children's Negotiation Tactics and Socio-Emotional Self-Regulation in Child-Led Play Experiences: The Influence of the Preschool Pedagogic Culture. Early Child Development and Care., online first.

Blaisdell, C., Arnott, L., Wall, K., \& Robinson, C. (2018). Look Who's Talking: Using Creative, Playful Arts-Based Methods in Research with Young Children Journal of Early Childhood Research.

Bronfenbrenner, U. (2009). The ecology of human development: Harvard university press.

Buckingham, D. (2017). Foreword. In R. Thomson, L. Berriman, \& S. Bragg (Eds.), Researching Everyday Childhoods: time, technology and documentation in a digital age (pp. vii-xi). London: Bloomsbury.

Burgess, D. (2008). Bridging the gap between parents, pupils and schools. Imaginative Minds Group Teaching Times.

Cahill, C. (2007). Doing Research with Young People: Participatory Research and the Rituals of Collective Work. Children's Geographies, 5(3), 297-312. doi:10.1080/14733280701445895

Christensen, P., \& Prout, A. (2002). Working with ethical symmetry in social research with children. Childhood, 9(4), 477-497.

Craft, A. (2012). Childhood in a digital age: creative challenges for educational futures. London Review of Education, 10(2), 173-190. doi:10.1080/14748460.2012.691282

Dockett, S., \& Perry, T. (2007). Transitions to School: Perceptions, Expectations, Experiences: UNSW Press. 
Dunlop, A. W., \& Fabian, H. (2010). Informing transitions in the early years. Research Policy and Practice. London: McGraw-Hill. Open University Press.

Edwards, S. (2013). Digital play in the early years: a contextual response to the problem of integrating technologies and play-based pedagogies in the early childhood curriculum. European early childhood education research journal, 21(2), 199212. doi:10.1080/1350293X.2013.789190

Edwards, S., Henderson, M., Gronn, D., Scott, A., \& Mirkhil, M. (2017). Digital disconnect or digital difference? A socio-ecological perspective on young children's technology use in the home and the early childhood centre. Technology, pedagogy and education, 26(1), 1-17. doi:10.1080/1475939X.2016.1152291

EECERA. (2015). EECERA Ethical Code for Early Childhood Researchers Retrieved from http://www.eecera.org/custom/uploads/2016/07/EECERA-EthicalCode.pdf

Fisher, J. (2013). Starting From The Child: Teaching And Learning In The Foundation Stage: Teaching and Learning from 4 - 8 (4th ed.). Maidenhead: McGraw-Hill Education.

Fleer, M. (2017). Digital playworlds in an Australian context: supporting double subjectivity. In P. H. Bruce \& M. Bredikyte (Eds.), The Routledge International Handbook of Early Childhood Play (pp. 289-304). Oxon: Routledge.

Gibbs, S. (2015). Hackers can hijack Wi-Fi Hello Barbie to spy on your children. The Gaurdian. Retrieved from https://www.theguardian.com/technology/2015/nov/26/hackers-can-hijack-wi-fihello-barbie-to-spy-on-your-children

Gray, C., Dunn, J., Mitchell, D., \& Moffett, P. (2017). Mobile devices in early learning. Evaluating the use of portable devices to support young children's learning. Retrieved from NI:

Gray, C., Dunn, J., Moffett, P., \& Mitchell, D. (forthcoming 2018). Child Mentors, Virtual Tours and Adult Protégées: Young Children's Experiences with Tablet Devices. In I. Berson, R., Berson, M.J., Gray, C. (Ed.), Participatory Methodologies to Elevate Children's Voice and Agency. Research in Global Child Advocacy Series. Charlott, North Carolina: IAP (Information age publishing),

Harcourt, D., \& Conroy, H. (2005). Informed assent: ethics and processes when researching with young children. Early child development and care, 175(6), 567-577. doi:10.1080/03004430500131353

Holloway, D., \& Green, L. (2016). The Internet of toys. Communication Research and Practice, 2(4), 509-519.

Kardaras, N. (2016). Glow Kids: How Screen Addiction Is Hijacking Our Kids-and How to Break the Trance: St. Martin's Press.

Lave, J., \& Wenger, E. (1991). Situated Learning: Legitimate Peripheral Participation: Cambridge University Press.

Levin, D. E., \& Rosenquest, B. (2001). The Increasing Role of Electronic Toys in the Lives of Infants and Toddlers: Should We Be Concerned? Contemporary Issues in Early Childhood, 2(2), 242-247. doi:10.2304/ciec.2001.2.2.9

Levy, R. (2009). 'You have to understand words ... but not read them': young children becoming readers in a digital age. Journal of Research in Reading, 32(1), 75-91. doi:10.1111/j.1467-9817.2008.01382.x 
Livingstone, S., Mascheroni, G., \& Staksrud, E. (2018). European research on children's internet use: assessing the past and anticipating the future. New Media and Society, 20(3), 1103-1122.

Marsh, J. (2005). Popular Culture, New Media and Digital Literacy in Early Childhood: RoutledgeFalmer.

Marsh, J., Plowman, L., Yamada-Rice, D., Bishop, J., \& Scott, F. (2016). Digital play: a new classification. Early Years, 36(3), 242-253. doi:10.1080/09575146.2016.1167675

Marsh, J., Plowman, L., Yamada-Rice, D., Bishop, J. C., Lahmar, J., Scott, F., . . . Winter, P. (2015). Exploring Play and Creativity in Pre-Schoolers' Use of Apps: Final Project Report. Retrieved from Accessed at: www.techandplay.org.:

Mascheroni, G., \& Holloway, D. (2017). The Internet of Toys: A report on media and social discourses around young children and IoToys. . Retrieved from

Merchant, G. (2007). Writing the future in the digital age. Literacy, 41(3), 118-128.

Moxley, D. P., Bishop, J., \& Miller-Cribbs, J. (2018). Photovoice methods in social work: Using visual and narrative techniques in participatory research and practice: Springer Publishing Company.

Palaiologou, I. (2016a). Children under five and digital technologies: implications for early years pedagogy. European early childhood education research journal, 24(1), 5-24. doi:10.1080/1350293X.2014.929876

Palaiologou, I. (2016b). Teachers' dispositions towards the role of digital devices in play-based pedagogy in early childhood education. Early Years, 36(3), 305-321. doi:10.1080/09575146.2016.1174816

Palmer, S. (2015). Toxic Childhood: How The Modern World Is Damaging Our Children And What We Can Do About It: Orion.

Plowman, L., \& McPake, J. (2013). Seven Myths About Young Children and Technology. Childhood Education, 89(1), 27-33. doi:10.1080/00094056.2013.757490

Plowman, L., McPake, J., \& Stephen, C. (2008). Just picking it up? Young children learning with technology at home. Cambridge Journal of Education, 38(3), 303319. doi:10.1080/03057640802287564

Scott, F., \& Marsh, J. (2018). Digital Literacies in Early Childhood. Curriculum and Pedagogy. Oxford Research Encyclopedia of Education, Online Publication Date Feb 2018. doi:10.1093/acrefore/9780190264093.013.97

Tudge, J. (2008). The Everyday Lives of Young Children: Culture, Class, and Child Rearing in Diverse Societies. Cambridge: Cambridge University Press.

Weisner, T. S. (2002). Ecocultural understanding of children's developmental pathways. Human Development, 45(4), 275-281. doi:10.1159/000064989

Yelland, N. (2015). Playful Explorations and New Technologies. In J. Moyles (Ed.), The Excellence of Play: McGraw-Hill Education.

Yelland, N., \& Gilbert, C. (2017). Re-imagining play with new technologies In L. Arnott (Ed.), Digital Technologies and Learning in the Early Years. London: SAGE.

Yin, R. K. (2013). Case study research: Design and methods: Sage publications.

Appendix 1

\begin{tabular}{|l|l|l|}
\hline Ecological Realm & Component Parts & Coding Structure \\
\hline Ecology of Self & $\begin{array}{l}\text { 1. Child in relation to } \\
\text { the self (autosphere) }\end{array}$ & $\begin{array}{l}\text { 1. Children's } \\
\text { Developmental Play } \\
\text { Instrument a }\end{array}$ \\
\hline
\end{tabular}




\begin{tabular}{|c|c|c|}
\hline & 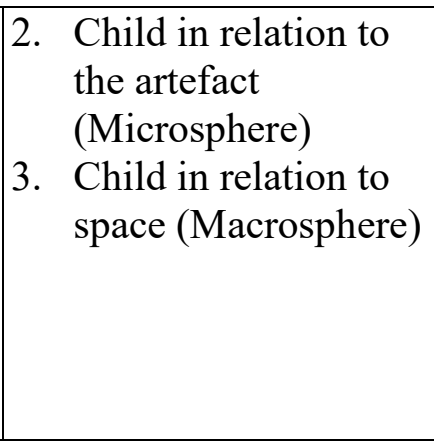 & $\begin{array}{l}\text { multidimensional } \\
\text { psychological tool for } \\
\text { examining children's } \\
\text { play (Chazan et al, 2016) } \\
\text { that provides a synthesis } \\
\text { between the inner } \\
\text { functions of play and the } \\
\text { interactions with the } \\
\text { environment. }\end{array}$ \\
\hline Ecology of Exosphere & $\begin{array}{l}\text { 1. Adult-child } \\
\text { interactions } \\
\text { 2. Child-child } \\
\text { interactions } \\
\text { 3. Mixed adult- } \\
\text { child/child-child } \\
\text { interactions } \\
\text { 4. Agency and power }\end{array}$ & $\begin{array}{l}\text { 1. Julie Fisher's (Fisher, } \\
\text { 2013) categorisation of } \\
\text { pedagogical interactions } \\
\text { provided a sense of } \\
\text { children's ownership of } \\
\text { the play experience. } \\
\text { 2. Broadhead's Social Play } \\
\text { Continuum (2010) } \\
\text { offered both an indicator } \\
\text { of social play but also an } \\
\text { indicator of relationships } \\
\text { between child and } \\
\text { artefacts, driven from } \\
\text { Broadhead's focus on } \\
\text { objects as central to } \\
\text { social interaction. } \\
\text { 3. Passivity versus } \\
\text { empowerment of digital } \\
\text { childhood (Craft, 2012). }\end{array}$ \\
\hline Ecology of Social World & $\begin{array}{l}\text { 1. } \begin{array}{l}\text { Structures and } \\
\text { constructions of } \\
\text { roles, rules and } \\
\text { regulations. }\end{array} \\
\text { 2. Learning structures } \\
\text { and practices }\end{array}$ & $\begin{array}{l}\text { 1. } \begin{array}{l}\text { Communities of Practice } \\
\text { and situated learning }\end{array} \\
\text { (Lave \& Wenger, 1991) } \\
\text { 2. Rogoff's (2008) cultural } \\
\text { ways of learning across } \\
\text { three planes. }\end{array}$ \\
\hline
\end{tabular}

Table 1: Analysis Structure 